\title{
Acerca de la responsabilidad penal: reconstrucción y sistematización de sus acepciones teórico-conceptuales en el campo de la criminología
}

\section{About criminal responsabily: reconstruction and systematization of its theorical-conceptual meanings in the field of criminology}

Osvaldo Héctor Varela* y Gabriela Rojas

Recibido: 31-05-2021 Breu**

Aceptado: $08-07-2021$

\section{Resumen}

La responsabilidad penal es un concepto estructural dentro de la criminología. Sin embargo, la formulación discursiva que soporta dicho concepto admite distintas lógicas y contenidos, siendo relevante realizar una sistematización y revisión de este constructo según sus diversos contextos de enunciación considerando las grávidas consecuencias teóricas e institucionales que se desprenden de su conceptualización. Por tal motivo, este trabajo tiene por objeto identificar las diversas

\section{Cómo citar}

Varela, O. H., \& Rojas Breu, G. Acerca de la responsabilidad penal: Reconstrucción y sistematización de sus acepciones teóricoconceptuales en el campo de la criminología. Revista Constructos Criminológicos. Recuperado a partir de https://constructoscriminologicos.uanl.mx/index.php/ cc/article/view/2

**https://orcid.org/0000-0003-2452-2121

Universidad de Buenos Aires, Argentina acepciones teórico-conceptuales que asume la responsabilidad penal en discursos referenciales de la criminología tales como el de la escuela de derecho penal liberal clásica, la escuela positiva, la nueva criminología, la criminología aplicada y la psicología jurídica asociada a la función clínica del derecho. El trabajo presenta un diseño de carácter descriptivo e interpretativo. Las categorías de investigación serán de exclusivo alcance cualitativo, al tiempo que los procedimientos consistirán en el relevamiento de fuentes secundaria y la revisión bibliográfica. Se concluye que la responsabilidad penal va a asumir distintos estatutos según la gravitación y conceptualización de los elementos que la integran: la reacción penal, el acto delictivo y el autor de dicho acto. De esta manera, la responsabilidad podrá ser consabida como responsabilidad moral, social, judicial o subjetiva. Del relevamiento expuesto, no obstante, es dable extraer un elemento recurrente: el ostracismo al que es compelida la dimensión subjetiva, lo cual ubica a la psicología jurídica en posición de recuperar y 
preservar aquella dimensión para que la pena no sea degradada a la lógica del castigo.

Palabras clave: Prisión, Criminología, Psicología Jurídica, Derecho Penal, Responsabilidad Penal. and preserve that dimension so that the penalty is not degraded to the logic of the punishment.

Keywords: Prison, Criminology, Legal Psychology, Penal Law, Criminal Responsability.

\section{Abstract}

Criminal responsability is a structural concept within criminology. However, the discursive formulation that supports this concept admits different logics and contents. It is relevant to carry out a systematization and review construct according to its various enunciation contexts, considering the heavy theoretical and institutional consequences that emerge from its conceptualization. Then, this work aims to identiy the various theoretical-conceptual meanings that criminal responsability asumes in referential discourses of criminology such as that of the classical school, the positive school, the new criminology, applied criminology and legal psychology associated with the clinical function of law. The Works presentes a descriptive and interpretive design. The research categories will be exclusively qualitative in scope, while the procedures will consist of the survey of secondary sources and the bibliographic review. It is concluded that criminal responsibility will assume different statutes according to the gravity and conceptualization of the elements that comprise it: the criminal reaction, the criminal act and the author of said act. In this way, responsibility may be known as moral, social, judicial or subjective responsibility. However, from the exposed survey, it is possible to extract a recurring element: the ostracism to which the subjective dimension is compelled, which places legal psychology in a position to recover

\section{INTRODUCCIÓN}

El concepto de responsabilidad penal es un concepto estructural dentro de la criminología e interpela un aspecto sensible del mismo. En efecto, de su delimitación y conceptualización se desprenderán, entre otras cuestiones, respuestas de naturaleza coercitivas y punitivas, diseños de abordajes específicos, estrategias preventivas y responsivas para la regulación del acto, políticas criminales para la reducción del delito y su reincidencia. Sin embargo, la formulación discursiva que soporta dicho concepto admite distintas lógicas y contenidos, siendo inexorable revisar y sistematizar estas divergencias con el fin de recortar el concepto y poder brindar insumos teóricos que aporten claridad al momento de responder acerca de la responsabilidad del sujeto infractor. Pues, claramente, la pregunta admite en un mismo enunciado distintas coordenadas de enunciación. Reconstruir el contexto de enunciación de ese enunciado es objeto de este trabajo.

Por lo tanto, es factible formular la pregunta problema en los siguientes términos: ¿Cómo queda cifrada la responsabilidad penal en el campo de la criminología asumiendo que este es un saber polifónico? O, ¿con qué elementos podemos cernir la responsabilidad penal en el campo de la criminología? 
Antes bien, se impone definir la variable a estudiar: la responsabilidad penal. Este artículo la define en tanto consecuencia jurídica derivada de la comisión de un hecho tipificado en la ley penal por un sujeto imputable, siempre que dicho hecho sea antijurídico, además de punible. La consecuencia jurídica será la sanción penal. Por lo tanto, esta variable admite tres elementos: el hecho tipificado, el autor de dicho acto y la consecuencia jurídica. Estos tres rasgos asumirán sentidos diversos según las escuelas indagadas en el presente artículo, portando esto consecuencias acusadas en el plano teórico e institucional.

Sería posible profundizar esta definición atendiendo a la vinculación entre la responsabilidad penal y la culpabilidad, lazo estructurante y estructural: considerando la elaboración doctrinaria referente a la Teoría del Delito (desde la línea finalista), la responsabilidad sucede a la culpabilidad toda vez que sólo será penalmente responsable quien haya sido considerado culpable: la responsabilidad es pensada como capacidad de respuesta por una culpabilidad, capacidad que admite la posibilidad de ejercer un reproche jurídico al agente del acto: será culpable aquel que habiendo podido obrar de otro modo, es decir, motivado en la norma, no lo haya hecho. Recién luego de este debate, puede determinarse la responsabilidad de un sujeto respecto de una acción (Zaffaroni, 2002). Por lo tanto, para analizar la responsabilidad es imperioso remitirse a la noción de culpabilidad y el elemento central con la que ésta se explica: el reproche jurídico. ¿Y cómo se responde a dicho reproche? Mediante la pena, consecuencia jurídica por excelencia.
De lo expuesto se desprende que los tres rasgos integrados en la responsabilidad penal se vincularán no solo en términos objetivos sino apelando a la subjetividad cifrada en clave de culpabilidad.

Ahora bien, es dable recordar la pregunta que insta este artículo y complejizarla a la luz de la definición de la variable a estudiar: ¿En qué consiste la responsabilidad penal desde las diversas perspectivas criminológicas? ¿La culpabilidad implicada en ella es asumida en los mismos términos por todas ellas? ¿Qué vinculación se puede pensar entre el delito y la pena? Si respondemos a la exigencia de sintetizar la pregunta problema, finalmente podemos formular la siguiente: ¿Qué acepciones teóricoconceptuales asume la responsabilidad penal en el campo de la criminología?

La hipótesis sobre la cual descansa este artículo responde a la pregunta problema en los siguientes términos:

- la responsabilidad penal admitirá distintas acepciones teórico-conceptuales según las distintas voces que integren el saber polifónico de la criminología.

- Dichas acepciones se recortarán en función de la variación de sus dimensiones: 1) el agente que debe responder por el acto delictivo, 2) el objeto del reproche (el autor o el acto), 3) la consecuencia jurídica o reacción penal en términos de la pena.

De esta manera, este trabajo tendrá por objeto identificar el concepto de responsabilidad penal en discursos estructurales del saber criminológico: el discurso de la escuela de 
derecho penal liberal clásica, la escuela positiva, la nueva criminología, la criminología aplicada y la psicología jurídica asociada a la función clínica del derecho.

Determinadas referencias teóricas constituyen antecedentes clave de este artículo. Es dable aclarar, no obstante, que si bien abundan referencias que dan cuenta de la responsabilidad penal en el campo del derecho penal, este trabajo basa su indagación en el entrecruzamiento de esta disciplina con otros campos de conocimiento tales como la criminología y la psicología, dado que desde este lugar se hace posible responder a la pregunta que motoriza esta producción. Al respecto, diversos autores han trabajado el concepto de responsabilidad penal en el pensamiento criminológico al interior de varias de sus escuelas (Baratta, 2004, Anitúa, 2005, Elbert, 2010, Zaffaroni, 2003, 2005, 2011, 2012, Prieto, 2004, Zaffaroni, Slokar, \& Alagia, 2002). Por otro lado, autores que engrosan el campo de la psicología jurídica han trabajado el concepto en su interlocución con la dimensión subjetiva, dando cuenta de aspectos particulares del vínculo. Llull Casado $(2015,2019)$ aborda la pregunta por la responsabilidad en el campo penal en posible diálogo con aquella dimensión tratando de cernir específicamente ese resto que escapa al abordaje jurídico.

En esta línea, Rodríguez, J. (2021) va a articular el acto con la responsabilidad, distinguiéndola de la culpa: "El acto (en la realidad) hace al sujeto responsable (...) mientras que la culpa atormenta al yo sin causa y sin tregua" ( $p$. 11). Asimismo, destaca dos cualidades de la responsabilidad moduladas por la culpa: la objetiva y la subjetiva: "la responsabilidad objetiva es una responsabilidad sin culpa. Consiste en la obligación de reparar el daño (...). La responsabilidad subjetiva supone la culpa, porque he sido yo quien causó el daño" (p. 1). Tendrlaz \& García (2008), Gérez Ambertín, Sarrulle, Carol, Elmiger, Medina, Rigazzio, Sialle \& Tosta Berlinkc (2005, 2006, 2010) desarrollan la responsabilidad penal en su articulación con la culpa, la pena y el sujeto implicado en el acto delictivo admitiendo en su análisis tanto la dimensión subjetiva como los dispositivos sociales que hacen posible la sanción penal. Pujó (2010), por su parte, también realiza aportes acerca de la relación del acto criminal con la responsabilidad y el castigo en la estructura subjetiva.

Estos antecedentes no agotan el campo de la materia, pero son los pilares que permitieron gestar este producto, cuya limitación se encuentra en el recorte mencionado y su pretensión obedece a iniciar una posible conceptualización de la responsabilidad penal en sus diversas acepciones. Entendemos que este aporte es relevante toda vez que responde a campos pendientes de indagación al tiempo que la necesidad de dominar cabalmente el constructo de referencia cuenta con plena vigencia. En efecto, tanto en espacios académicos como en los que habitan las instituciones dedicadas a la ejecución de la pena la pregunta por la responsabilidad penal insiste y de su respuesta se desprenden grávidas consecuencias. Es innegable que entender plenamente la pregunta supone comprender su contexto de enunciación, requisito radical para ofrecer una respuesta profesional que resista su degradación a un mero acto técnico. 


\section{METODOLOGÍA}

El trabajo se inscribe en un marco de coordenadas que incluyen los aportes de la Criminología y la Psicología Jurídica entre sus referencias teóricas. El tipo de diseño será de carácter descriptivo e interpretativo. Las categorías de investigación serán de exclusivo alcance cualitativo, al tiempo que los procedimientos consistirán en el relevamiento de fuentes secundaria (particularmente, la revisión bibliográfica) que permita operar un movimiento de conceptualización teórica. Las mentadas fuentes son seleccionadas en virtud de ser consideradas referenciales dentro de la comunidad científica y de asistir en la finalidad de identificar los elementos supra referidos.

\section{RESULTADOS}

\subsection{La responsabilidad en la Escuela de Derecho} Penal Liberal Clásica

Pensar la responsabilidad penal en el marco de la matriz conceptual propuesta por la escuela de derecho penal liberal clásica exige introducir elementos propios de aquel que hacen asequible la pregunta por aquel constructo toda vez que dan cuenta del fundamento del porqué se debe responder por algún tipo particular de acto. Uno de estos elementos es el fundamento de la ley que, en definitiva, va a redundar de algún modo en el fundamento de la pena:

Las leyes son las condiciones con que hombres independientes y aislados se unieron en sociedad, fatigados de vivir en un continuo estado de guerra y de gozar una libertad convertida en inútil por la incertidumbre de conservarla. Sacrificaron una parte de ella para gozar la restante con seguridad y tranquilidad. La suma de todas estas porciones de libertad sacrificadas al bien de cada uno constituye la soberanía de una nación (Beccaria, 1764: 72).

De esta consabida afirmación se desprende la idea de que la renuncia a una cuota de libertad es el origen de la ley, fundamento del derecho y habilitación del castigo. Ahora bien, zquiénes son los agentes de la renuncia? Hombres libres e iguales. Se parte de la idea de que el contrato social es acordado por seres independientes que suscriben desde escenarios equivalentes, sin coacción ni inequidad. Y firman con la renuncia a dicha cuota de libertad. Mas esta renuncia habrá de defenderse de aquellos que motivados por intereses privados no asuman la suya propia.

Establecido el fundamento del derecho, surge la pregunta por el lugar que ocupa en esta escuela la consecuencia jurídica de violar el derecho que tiene por fin proteger el pacto social: esta consecuencia jurídica, es decir la pena, tendrá como fin la defensa del contrato y como interlocutor destacado, al tejido social objeto de defensa. El delincuente no será el destinario dilecto de la reacción penal, sino el conjunto social que sostiene el contrato: "el derecho penal y la pena eran considerados por la escuela clásica no tanto como un medio para modificar al sujeto delincuente, sino sobre todo como un instrumento legal para defender a la sociedad del crimen" (Baratta, A., 2004: 23). La reacción penal, entonces, será un instrumento legal disuasivo. Mas esta reacción se limita por el mismo cuerpo legal que inhibe el exceso de la potestad punitiva del Estado en función 
de la necesidad, la utilidad y el principio de legalidad. La pena no solo es disuasiva sino que tendrá por función confirmar la vigencia del pacto social que compele a tal renuncia. Ahora bien, el rasgo disuasivo de la pena le otorga a ésta estatuto de motivo sensible:

Se requerían motivos sensibles para desviar el ánimo despótico de cada hombre de su intención de volver a sumergir las leyes de la sociedad en el antiguo caos. Estos motivos sensibles son las penas (...). Digo motivos sensibles porque la experiencia ha hecho ver que la masa no adopta principios estables de conducta sino por motivos que inmediatamente impresionan los sentidos (Beccaria, 1764: 72).

De esta manera, la pena está prevista como un mecanismo de prevención general, mecanismo que descansa sobre la elocuencia de la pena en su capacidad de impactar en los sentidos de los testigos que decodificarán la sanción en los modos del ejemplo.

De lo expuesto, entonces, se desprende que la pena es una reacción a una usurpación privada que reedita la amenaza del restablecimiento del caos previo a la legalidad. Y esta usurpación privada en clave de delito va a ser lo que el magistrado recorte como materia de imputación y respuesta. Pero esta reacción judicial no tendrá por referencia al ejecutivo ni al propio "espíritu", dirá Beccaria en la obra citada, sino al texto de la ley: se instala entonces el principio de legalidad y, con él, la concepción de garantías apuntaladas en una referencia previa y externa a cualquier diálogo especular. La ley positiva, así, busca emular la regulación legal intrínseca a las fuerzas universales. En términos de Carrara (1889), el derecho buscará erigirse en tanto "ley que es absoluta, porque es constitutiva del único orden posible para la humanidad, según las previsiones y la voluntad del Creador" (p. 27-28). En este sentido, para Carrara el derecho admitirá una parte teórica y una práctica: la primera cuenta con el fundamento lógico de la verdad en tanto efecto de la naturaleza de las cosas, desprendimiento del orden mismo e inmutable de la materia. La segunda, en cambio, encuentra tal fundamento en la ley entendida en términos positivos.

La ley positiva, entonces, será para esta escuela el fundamento para delimitar el acto que resulte lesivo: la teoría del delito va a trazar las coordenadas que admitan la ulterior delimitación de un evento contario al pacto social en tanto delito. Pues el delito va a ser un hecho jurídicamente calificado, es decir, una violación del derecho. $Y$ de esta manera, el peso recaerá en el acto eclipsando a su autor que no será materia de discusión ni de indagación: la lectura y abordaje objetivo del delito predominarán en el sistema de Carrara y en la escuela clásica en general, en detrimento de consideraciones subjetivas vinculadas al infractor. Porque es el delito el que inaugura la reacción punitiva toda vez que este lesiona en clave de impunidad la vigencia del contrato social: "El fin de la pena no es la retribución -afirma Carrara- ni la enmienda, sino la eliminación del peligro social que sobrevendría de la impunidad del delito" (Baratta, A., 2004: 30).

Se van despejando los términos: por un lado, la responsabilidad penal se activará a partir de un 
acto que será el centro de la escena analítica judicial. Este acto, el delito, de acuerdo a la postura filosófica racionalista e iusnaturalista, es considerado un ente jurídico y producto de una abstracción. Se aísla el delito de su inscripción originaria y se le imprime una estructura propia con significado jurídico autónomo, "que surge de un principio a su vez autónomo, metafísicamente hipostasiado: el acto de la libre voluntad de un sujeto" (Baratta, A., 2004: 31).

Será este hecho delictivo el que incorporado a la lógica del silogismo impulse o no el proceso de criminalización. De esta manera, el silogismo tendrá sus tres piezas conformadas de la siguiente manera: la premisa mayor descansará en la ley positiva; la premisa menor, en el acto que, de resultar violatorio del corpus normativo vigente o no, derivará en la conclusión: la pena o ausencia de la misma. La pena será una respuesta que tiene por fin preservar el contrato vigente y defender a quienes hayan contribuido con aquel depósito público de aquellos que lo amenacen.

El silogismo, entonces, excluye al sujeto infractor en sus piezas. El acto agotará todos los elementos de análisis que deriven o no en una reacción penal. De esta manera, se puede advertir que el reproche jurídico se piensa de manera mecánica para todo infractor. Es decir, la escuela clásica asumirá a modo de hipóstasis la libre voluntad del mismo para decidir si actuar conforme a derecho o de manera lesiva al respecto. Por lo tanto, la culpabilidad será un factor que se agota en los términos objetivos asumidos por el acto delictivo: el delito será la variable a interrogar y su autor, imputable y responsable a priori en tanto aquel hecho es efecto de un movimiento voluntario y libre:

...la escuela liberal clásica (...) se detenía sobre todo en el delito entendido como concepto jurídico, es decir como violación del derecho y también de aquel pacto social que se hallaba (...) en la base del Estado y del derecho. Como comportamiento, el delito surgía de la libre voluntad del individuo, no de causas patológicas, y por ello, desde el punto de vista de la libertad y de la responsabilidad moral de las propias acciones, el delincuente no era diferente, según la escuela clásica, del individuo normal (Baratta, 2004: 23).

De esta cita se pueden advertir al menos dos cuestiones centrales: por un lado, que el centro gravitatorio de esta escuela descansa sobre el acto delictivo. Es el delito el que insta una reacción prevista en términos penales. $Y$, por el otro, que su agente comporta libertad para actuar vulnerando al derecho protector del contrato social. Por lo tanto, el autor del delito no debe ser indagado en sus características intrínsecas dado que la motivación del delito queda suturada en la fórmula axiomática del libre albedrío. De esta manera, el delito es una lesión al pacto social y la culpabilidad no es una pregunta que encuentre alojamiento en el proceso toda vez que el libre arbitrio la neutraliza y anticipa. De esta manera, la responsabilidad penal se encuentra homologada a la responsabilidad moral.

Sucintamente, es posible afirmar que el deslizamiento de la responsabilidad penal a la responsabilidad moral ilustra los términos 
que integran la primera: el acto será el centro de análisis y el elemento clave que motive la respuesta penal; el autor del mismo se presumirá taxativamente, con estatuto de hipóstasis, dueño de conducir su acción, razón que excluye el componente subjetivo de las indagaciones judiciales; la consecuencia jurídica, finalmente, se preverá en términos de prevención general. En este sentido, el sujeto infractor será quien ofrezca en su condena el ejemplo sobre el cual soportar la preservación del contrato social en clave preventiva, útil y necesaria. Es posible agregar algo a esta conclusión parcial: la regulación de la pena descansa en el acto y no en el autor y está prevista por la referencia legal que, por definición, excluye la discrecionalidad de las ponderacionaes que graviten las decisiones judiciales.

\subsection{Escuela positiva}

El positivismo comportó un impacto elevado sobre todo los discursos pretensamente científicos. La criminología, no fue la excepción sino, contrariamente, su confirmación:

Así pues, desde este enfoque comenzó a tener relevancia la pregunta sobre cómo detectar al sujeto criminal (según la clasificación de Enrico Ferri), basándose en la concepción positivista del delito de la Escuela Ingles de Galton (de antropometría criminal) y la Escuela Italiana de César Lombroso (de antropología criminal) (Varela, 2020: 27).

El hombre criminal capturado por redes de categorías que admiten predicción y medición desplaza al acto delictivo como centro de la respuesta punitiva. En efecto, con la criminología positiva el delito cede su lugar al delincuente, alejándose de la postura racionalista e iusnaturalista de la escuela clásica. De esta manera, es dable anticipar que la voluntad y libertad del infractor postuladas por la escuela clásica van a ser sustituidas por el determinismo biológico, psicológico y social. El efecto inexorable de esta premisa es el concepto de peligrosidad. ¿La peligrosidad de quién? Del delincuente.

El delincuente será el recorte asumido por esta escuela a los fines de delimitar las causas de la criminalidad en clave determinista y el modo de neutralizar las mismas en el marco de la pena. Estos esfuerzos son conceptualizados en términos de paradigma etiológico y correccionalismo, respectivamente. $\mathrm{Y}$ esta búsqueda de causas es correlato de la reversión del movimiento de abstracción que operara la escuela clásica:

La reacción contra el concepto abstracto de individuo conduce a la escuela positiva a afirmar la exigencia de una comprensión del delito que no se detenga en la tesis indemostrable de una causalidad espontánea por medio de un acto de libre voluntad, sino que se dirija a encontrar todo el complejo de las causas en la totalidad biológica y psicológica del individuo, y en la totalidad social en la que la vida del individuo se inserta. (Baratta, 2004: 32).

Esta escuela, entonces, busca revertir el movimiento de abstracción ejercido por la escuela clásica respecto del delito y del autor para colmarlo de postulados naturalistas positivistas que abonen medidas preventivas y correctivas. Mas, en el marco de esta escuela 
la prevención cursa con la lesión al texto de la ley y a las garantías. Ejemplo de esta afirmación lo ofrecen las medidas pre-delictuales. ¿Cuál es la clave que habilita el canal de la concepción del delincuente sin delito? La peligrosidad soportada en el determinismo. En efecto, a la tesis de la imputabilidad absoluta del delincuente y la responsabilidad moral plena propuesta por la escuela clásica, se opone el determinismo positivista dando lugar a una serie de consecuencias que pasaremos a revisar a continuación.

Una de las consecuencias antedichas redunda en el estudio de los criminales alcanzando clasificaciones que versan en la tipología del autor, detectando mulfifactorialidad en la génesis delictiva y trocando correlación por causación. La visión particularmente antropológica de Lombroso (que en sus textos tardíos niega la exclusión de factores ajenos a la biología) es acompañada y complementada por la incorporación de factores psicológicos de la mano de Garófalo y por factores sociológicos, por Ferri. Este último, en su libro Sociologia criminale (1900), agrupa la matriz etiológica del delito en tres clases de factores: antropológicos, físicos y sociales. Este conjunto de factores conforman una matriz categorial del delincuente determinado a ser tal. El comportamiento delictivo no es más, entonces, que efecto y expresión de esta realidad en la que el sujeto se inserta. Y este comportamiento halla tal nivel de determinismo que Lombroso (1876) Ilega a afirmar que el delito es un fenómeno tan necesario, como el nacimiento, la muerte, la concepción, es decir, un "ente natural" determinado por causas biológicas de naturaleza sobre todo hereditaria.
De esta manera, el autor del delito evidencia las características anómalas de su agente: el delito será un elemento sintomático de la personalidad. O, dicho en términos de Grispigni (1947), un síntoma de triple filiación: primero, síntoma de una individualidad psíquica; segundo, síntoma de peligrosidad; y tercero, síntoma de un defecto psíquico. Por lo tanto, el delito es la vía de acceso a su agente, quien según los rasgos que porte será merecedor de un determinado tratamiento. $\mathrm{Y}$ esto nos conduce al siguiente punto.

Una segunda consecuencia reposa sobre el sentido de la pena: asiste al respecto el correccionalismo que otorga valor y orientación a la pena sin negar por esto la defensa social que la misma ya ostentaba. Si el delito era solidario de factores que habitan al criminal, entonces éste es un ser diferente al que hay que corregir. Junto al correccionalismo, entonces, aparece la dimensión de la patología y del tratamiento. Y si hablamos de patología, negamos la transgresión voluntaria: el "déficit de racionalidad constituyó (...) tanto la explicación del comportamiento desviado (...) como las variadas justificaciones" (Simonetti, J., \& Virgolini, J., 2003: 103). Así, el sentido enunciado de la pena no será la disuasión sino la corrección y el tratamiento.

Una tercera consecuencia, íntimamente vinculada con las anteriores, tiene por central la concepción de la peligrosidad como elemento decisivo de la punibilidad. Es el autor quien determinará la respuesta penal y no la referencia previa de la ley enmarcada en el principio de legalidad. La discrecionalidad abonada por la individualización de la pena en el marco de la peligrosidad anula la referencia a la ley como 
regulación tercera y ajena a la lógica especular.

En efecto, la escuela positiva va a hacer depender la regulación de la pena de las características del autor y no del acto y, por tanto, introduce el riesgo de la indeterminación de la pena (Baratta, 2004). Pues en esta concepción, el crimen deja de ser un hecho enteramente jurídico para alcanzar un estatuto ontológico y ser efecto de una patología cuya "cura" no puede predecirse en unidades de tiempo. El tratamiento durará lo que la patología requiera. De esta manera, la peligrosidad es fundamento de la punibilidad. En tal sentido, Garófalo (1885) establece que la pena debe aplicarse considerando la temibilidad del delincuente, la cual es integrada por dos elementos: un elemento objetivo dado por el delito y uno subjetivo aportado por el criminal.

El objeto que nosotros nos proponemos no es fijar la cantidad de dolor que corresponda al robo (...) sino el de designar el medio represivo exactamente apropiado, esto es, el obstáculo capaz de alejar el peligro. Por lo tanto, para nosotros, el problema debe ser enunciado en los siguientes términos: ¿cuál es el medio para determinar la perversidad constante del delincuente y el grado de sociabilidad que le queda? (Garófalo, 1885: 200).

Una cuarta consecuencia aborda de manera directa el tema que nos compete: la responsabilidad penal. En efecto, de lo expuesto hasta aquí se despejan términos con claridad respecto a las tres dimensiones de esta variable: el acto como ente natural sintomático de la anomalía patológica de su autor; el autor como un ser peligroso y determinado a cometer el comportamiento por múltiples factores que lo inscriben en una tipología particular y la consecuencia jurídica: la pena entendida en términos correccionalistas en el marco de una ideología de tratamiento. Ahora bien, queda por saldar una elipsis: si el delincuente no es responsable de su acto por haber estado determinado a realizar el mismo, ¿sobre quién reposa esta responsabilidad? Pues en este contexto discursivo y conceptual, la retribución jurídica o ética de la pena no pueden ser sostenidas. Esto cobra mayor elocuencia si citamos frases reconocidas de la mesología criminal, de corte positivista, tales como "las sociedades tienen los criminales que se merecen" o "todo el mundo es culpable menos el delincuente" (Lacassagne, citado por Anitúa, G., 2005: 192).

En este sentido, la responsabilidad moral de la escuela clásica será sustituida aquí por la responsabilidad social: "Si no es posible imputar el delito al acto libre de una voluntad (...), sí lo es sin embargo referirlo al comportamiento de un sujeto, y esto explica la necesidad de una reacción de la sociedad" (Baratta, 2004: p. 33). La escuela positiva entonces convierte al tejido social en responsable de contener el peligro que revisten determinados infractores más allá del delito que evidencie aquel. Y esta responsabilidad se operacionaliza tanto en cláusulas de defensa social bajo la forma de "sustitutos penales" y como en la pena legitimada en su función curativa y reeducativa. En este apartado, entonces, se han podido delimitar los términos de la responsabilidad penal en tanto consecuencia jurídica derivada de la comisión de un hecho tipificado en una ley penal como delito por un agente. En este 
caso, el agente es punible y deberá responder con la pena por su acto. El reproche se le dirige a él pero la responsabilidad por el hecho admite otro actor: la sociedad que en su conjunto debe defenderse del peligro que la acecha. La escuela positiva convertirá la pena en tratamiento curativo y correctivo y al delito, en patología causada por factores bioantropológicos y sociológicos. Mas el delito o fenómeno criminal será concebido como dato ontológico preconstituido a la reacción social y al derecho penal. En este sentido, la responsabilidad social no solo recaerá en la reacción necesaria frente al crimen sino en el estudio de sus causas de manera independiente y autónoma respecto del derecho penal.

\subsection{Perspectivas críticas: la nueva criminología}

Las perspectivas criminológicas críticas se reencuentran en diversas miradas y constructos teóricos que no son posible de abordar en el presente artículo. No obstante, asistidos por la propuesta de Zaffaroni (2003), extraemos un rasgo de todas estas perspectivas que permite pensarlas como un corpus integrado: el cuestionamiento del poder. En efecto, esta nueva criminología va a desplazar una vez más el foco de interés: será el sistema penal y la reacción social parte destacada de las indagaciones de este saber en detrimento del acto criminal y de su agente, el criminal:

...en cierto momento, primero en función "del interaccionismo simbólico" y luego con la sociología del conflicto, la criminología extiende su ámbito al "sistema penal" (...) y, en definitiva la íntima conexión con el poder. De la "criminología centrada en la conducta criminal" se pasó a la llamada "criminología de la reacción social". (Zaffaroni, 2003: 8).

En este sentido, la criminología no será una ciencia que aísla entes divorciándolos de su inscripción macrosocial sino que se trata "de un saber cuya delimitación epistemológica se produce por efecto de una ligación a una columna vertebral, que es el sistema penal y su operatividad" (Zaffaroni, 2003: 19). Ahora la responsabilidad va a recaer no tanto en el autor del acto delictivo, sino en el autor de su selección y de la reacción penal.

$\mathrm{Si}$ nos adentramos en la relación entre la criminología y el poder, las denuncias encuentran en el modelo de ciencia positiva la causa no solo de la relación estructural entre ambos elementos, sino la condiciones para la asepsia con la que se desmiente esta vinculación (Anitúa, 2005). Esta maniobra reductora habilitada por un determinado modelo de ciencia legitima la pena como elemento para cristalizar un orden y reproducir las condiciones políticas. Ya no corregir, sino disciplinar "permitiendo una eficaz pervivencia de una microfísica del poder. La pretendida "cientificidad" dará forma y textura a esta nueva racionalidad, esto es, el consenso acerca de un orden social (político) determinado, incluso allí donde lo irracional irrumpe" (Rojas Breu, G., 2020: 37). Se introduce, entonces, el recorte de la criminalidad como un efecto de una trama de variables sociales, culturales, históricas, políticas, económicas no reductibles a la dimensión individual. Por tal motivo, el centro de gravedad de estas perspectivas estará puesto ya no en el sujeto infractor ni en el crimen, sino en la consecuencia jurídica entendida como reacción penal propia de una operatividad 
particular del sistema penal. Esto impone profundizar la indagación acerca del vínculo entre la criminología en tanto respuesta penal y la política como así también en el concepto de crimen desde este punto de vista.

En primer lugar, podemos afirmar que no es posible considerar la criminalidad por fuera del discurso jurídico ni como dato preconstituido. La consideración del crimen como un comportamiento definido por el derecho, y el rechazo del determinismo y de la consideración del delincuente como un individuo diferente, son aspectos esenciales de la nueva criminología (Baratta, A, 2004: 22). El crimen, entonces, es efecto del derecho. $Y$ el derecho es efecto de la política que encuentra en la criminología un recurso para cristalizar estructuras sociales determinadas: la relación entre política y criminología asume una condición necesaria, en tanto la primera recorta el orden público y sus lesiones: los crímenes (Simonetti, J., \& Virgolini, J., 2003). Esto supone que el rol social atribuido a la Criminología y el campo empírico sobre el que despliega su discurso se definen a partir de un orden social, el cual no es sino político. Es dable desagregar el vínculo entre criminología y política ubicando a la primera como herramienta dilecta para garantizar el control social. En palabras de Pavarini, la criminología es "una pluralidad de discursos (...) orientados hacia la solución de un problema común: cómo garantizar el orden social" (1983: 18).

Ahora bien, ¿por qué asumir el axioma por el cual el orden social asume rasgos políticos? Pues, porque se trata de los modos en los que se piensan y reproducen las relaciones sociales y económicas en el marco de un determinado orden normativo de base estatal. La selección y construcción de este orden y el ejercicio de la autoridad son objeto de la política: el principio de uniformidad y la conservación coactiva revelan este origen (Rojas Breu, 2020). Este componente coercitivo, monopolio legítimo del poder estatal, sostiene y habilita el derecho que preserva la integridad de dicho poder y a su vez éste está garantizado externamente por dicha coacción, por lo que se puede definir a la política como el arte de transformar tendencias sociales en formas jurídicas (Heller, 1992:223).

El orden es político y de su recorte se desprenden las diversas desviaciones que invitan a la gestación de la criminología como ciencia, negadora de su lazo con la política. Mas, esta relación no se agota aquí: la política dicta leyes e impone penas. La pena, entonces, no es sino un hecho político (Zaffaroni, R., 2011). Este autor va a bordear la pena en tanto concepto negativo pues no concede a la pena función positiva alguna y solo opera por exclusión. Por tal motivo, sustenta la "teoría agnóstica de la pena", es decir, una teoría que asume desconocer la función de la pena, ya que niega su capacidad de solucionar conflictos o de prevenirlos. La pena, entonces, será una consecuencia jurídica no necesariamente legítima, sino que se erige en un acto de poder político: "La pena no es más que un hecho de poder y la teorización en torno de la misma no pasa de ser una tentativa legitimante de todo el ejercicio del poder penal" (Zaffaroni, R., 2012: 282). Tobias Barreto, de la Escola de Recife, será insumo para aquel autor al momento de abordar la idea de pena como efecto político: el derecho y la guerra portarán similar fundamento, y en este punto 
se reencontrará el propio de la pena (Zaffaroni, R., 2012: 203 - 223).Y si la pena es un hecho político, la desigualdad la asiste y la compele a ser fuerza contraria que evite el reequilibrio de fuerzas. Por tal motivo, el autor va a ubicar al sistema penal como parte de una operatoria selectiva y reproductora de violencia.

Este lazo entre el poder político y el derecho ya es subrayado por Locke: "el poder político es derecho de dictar leyes bajo pena de muerte" (Simonetti, J., \& Virgolini, J., 2003: 98). Mas, esta obligación de obedecer bajo riesgo de sanción requiere un partenaire obligado: el sujeto dócil que convierta el interés ajeno en interés propio, autocensurado sobre la base de una moralidad que el sistema de penalidad estatal contribuyó a gestar. ¿Qué lugar entonces para los sujetos que escapan a la autocensura? Claramente este enfoque niega la patología y la anomalía y opone en cambio un análisis basado la estructura social en clave de denuncia. Acorde los desarrollos planteados por Grüner (2007), Virgolini y Simonetti (2003), entre otros, es condición del orden no solo la pretensión del Estado de mandar sino la construcción de ciudadanos que se conviertan sus propios vigilantes, de la subjetivación de la violencia objetiva renegada, fuente de legitimidad social (Grüner, 2007: 51). A falta de subjetivación de esta violencia, advendrá de manera externa la violencia hecha pena. En caso de advertir los nexos entre la obediencia y el poder político y ante la pretensión de revertir estas coordenadas del orden social, la masacre advendrá descosiendo los ropajes de la ideología científica que legitimaban la violencia (Basaglia, F., 1987).
Las posturas críticas denuncian la negación de la criminología positiva de su intimidad con la política a través de sus postulados técnicos y explicaciones etiológicas basadas en patologías individuales o sociales. Define los límites de su discurso autónomo divorciando el crimen de su origen político y social que impone un orden. Sin embargo, este orden es por definición social y es la resistencia a advertir esto la que niega la dimensión social del crimen. El poder político monopoliza el castigo en función de un crimen recortado como desobediencia a un determinado orden también político: los variados artefactos de castigo y de control punitivo pertenecen al ámbito de la política, puesto que la función social de establecer y mantener un orden es esencialmente coactiva (Virgolini, J.: 2005).

Ahora bien, el crimen y castigo son definidos a través de este orden. $Y$ ambos objetos serán apropiados por la criminología que los intuye como una operación externa. Criminología, política y orden, entonces, admiten inscribirse en un mismo eje al tiempo que se niegan mutuamente.

Lo expuesto hasta aquí permite advertir que la pena es un hecho político reactivo a un acto definido como delito a partir de coordenadas sociales y políticas. El centro del análisis es esa respuesta penal reconducida a su origen eclipsado por las concepciones previas: el control social al servicio de sostener un determinado orden que cristaliza diferencias preservándolas. Ahora bien, en esta matriz, ¿Cómo se puede pensar la responsabilidad penal? Dos de sus dimensiones ya fueron abordadas, pero resta profundizar respecto al agente de 
la respuesta y a la noción de culpabilidad implicado en ella. Respecto a la última, esta perspectiva entiende que la culpabilidad normativa, esto es, el reproche personalizado, entra en crisis junto con la deslegitimación del poder del sistema penal. La reproducción de la violencia y la selectividad de este sistema neutraliza este reproche, pues un juicio de reproche desigual está vacío de todo contenido ético (Zaffaroni, 2012: 265 - 270). De esta manera, se troca la culpabilidad en crisis por la Ilamada clínica de la vulnerabilidad, entendida esta como el riesgo a ser seleccionado por el sistema penal. La magnitud de este riesgo estará dada por factores que integran dos categorías: la posición o estado de vulnerabilidad y el esfuerzo personal por la vulnerabilidad. La primera es predominantemente social: consiste en la probabilidad de ser seleccionado y sufrir el proceso de criminalización por la sola pertenencia a una clase, grupo, estrato social, minoría, etc. asumiendo rasgos que correlacionen con un estereotipo. La segunda categoría, el esfuerzo personal, es predominantemente individual consistiendo en el grado de peligro o riesgo en que la persona se coloca a partir de la conducta que realice toda vez que lo haya decidido de manera autónoma. De esta manera, la culpabilidad por el injusto pasa a integrar un análisis más complejo dado por la culpabilidad por la vulnerabilidad (Zaffaroni, R., 2012: 270 - 281).

En este sentido, la reinserción social, no será un proceso de readaptación, sino de ruptura con las condiciones que inscriban al condenado en el estereotipo que insta la selectividad del poder punitivo, debilitando el nivel de vulnerabilidad ante el sistema penal y dejando en sombras el acto que instó la criminalización.

Ahora bien, si el crimen es un constructo solidario de coordenadas de poder deslegitimadas, el sujeto es aprehendido por su condición de vulnerabilidad por la cual no se le puede aplicar reproche alguno y la respuesta penal en sí misma carece de ética por su práctica selectiva y violenta, ¿quién asume la responsabilidad? Pues bien, lo será la agencia judicial. ¿En qué sentido? En el sentido etimológico, pues es quien responde ante el injusto, pero también en un sentido más crítico y reflexivo: si el poder ejercido por el sistema penal perdió legitimidad tras denunciarse la alianza con la inequidad antedicha, el procesado ya no tiene por qué responder legítimamente. En palabras del citado autor: "La responsabilidad es de la agencia judicial que debe responder ante el procesado y ante la comunidad, dando cuenta de la forma en que ejerce o administra su reducida cuota de poder limitador" (2012: 271). Se introduce, de paso, la función del derecho para esta escuela: limitar la violencia del sistema penal aspirando a la etización del derecho penal. Es la agencia judicial la que debe comportarse de manera ética frente al ejercicio de poder deslegitimado, procurando limitar el alcance de las maniobras de dicho poder.

Los términos que integran la variable responsabilidad penal se ven eclipsados por uno de ellos: la reacción penal, centro del análisis de esta corriente que convierte atribuye la responsabilidad a la agencia judicial, troca culpabilidad por vulnerabilidad del sujeto autor del hecho y ubica el acto como instancia que habilita un proceso de criminalización penal que dicha agencia judicial deberá limitar. 


\subsection{Perspectivas actuales de inscripción institucional: criminología aplicada y Modelo de Desistimiento}

Para analizar las dimensiones indagadas en este trabajo, la referencia texto legal vigente es un recurso necesario toda vez que este explicita, por un lado, la función de la pena y, por el otro, su vinculación con el delito y el autor. Por supuesto, las lecturas críticas trabajadas en el apartado anterior arrojarán luz sobre la doble vía analítica para vislumbrar la finalidad de las penas: la que se enuncia y la que se oculta. Sin embargo, el análisis del enunciado es insoslayable pues tiene efectos a nivel social, institucional, grupal e individual. Por tal motivo, encontramos en el artículo $1^{\circ}$ de la Ley de Ejecución de la Pena Privativa de la Libertad N. ${ }^{\circ} 24.660$, que fuera modificado en el año 2017 por ley 27.375, las siguientes formulaciones:

La ejecución de la pena privativa de libertad, en todas sus modalidades, tiene por finalidad lograr que el condenado adquiera la capacidad de respetar y comprender la ley, así como también la gravedad de sus actos y de la sanción impuesta, procurando su adecuada reinserción social, promoviendo la comprensión y el apoyo de la sociedad, que será parte de la rehabilitación mediante el control directo e indirecto.

El régimen penitenciario a través del sistema penitenciario, deberá utilizar, de acuerdo con las circunstancias de cada caso, todos los medios de tratamiento interdisciplinario que resulten apropiados para la finalidad enunciada (Ley 27.375/17, art. 1).
De la cita, es posible advertir una serie de consideraciones. En primer lugar, que la pena y el reproche recaen sobre el condenado, que es quien debe adquirir algo que no tiene: la capacidad para respetar y comprender la ley. La pena se piensa como una instancia en la que el sujeto pueda vincularse con la ley desde la observancia. Asimismo, se imprime una dimensión valorativa del acto delictivo al enunciarqueaquella comprensión debealcanzar también la gravedad de sus actos. Es decir, se adjetiva el acto en un sentido determinado y junto a este se especifica un elemento intrínseco a la pena de sesgo punitivo: la sanción. Finalmente, reedita el modelo de tratamiento pero agregando términos excluidos del texto legal antecesor tales como la rehabilitación que reconduce el reproche al condenado licuando al responsabilidad compartida con el tejido social a través del principio resocializador dado en la reinserción social a la que se aspira. Por tanto, la consecuencia jurídica, según esta letra, será una sanción que recaerá sobre un sujeto conminado a cumplirla por la comisión de actos graves.

Este imperativo legal encuentra asistencia en un corpus teórico determinado que orienta intervenciones institucionales en la actualidad. Son citas obligadas, en este punto, los aportes de la criminología aplicada y algunas de sus derivaciones: el Modelo de Riesgo-NecesidadResponsividad (Andrews \& Bonta, 2009) y el Modelo de Desistimiento. Esta corriente nace en respuesta a su antecesora, el "nothing Works" propulsado por Martinson (1979) y a la criminología crítica. EL modelo RNR 
incluye variables sociales y vinculares pero sin desagregarlas del sujeto infractor, razón por la cual sigue negando otros niveles de análisis para dar cuenta de la responsabilidad penal. Asimismo, centra la respuesta del condenado en factores de riesgo dinámicos y estáticos que indicarán necesidades criminogénicas orientadoras del diseño del tratamiento acorde patrones responsivos. No puede obviarse la reedición, en este punto, de concepciones previas. El marco teórico no niega lo social pero lo ubica a cuenta de lo individual diluyendo en este polo la complejidad irreductible de aquella dimensión. La pena recae enteramente en el infractor, sin convocatoria posible a otro actor que llega a enunciarse pero no a incluirse: la sociedad. Este actor queda diluido en esfuerzos espasmódicos o aislados que no llegan a tener sustento en matrices institucionales arraigadas.

Este modelo de gestión de riesgos, entonces, va a reforzar el imperativo de respuesta penal en términos de un sujeto autor de un acto grave. El sujeto será autor de este acto por factores que son estudiados de forma acabada, factores que no van a determinar la comisión del delito sino que lo van a explicar en el marco de la probabilidad prevista en el paradigma del riesgo. El aspecto dinámico del riesgo niega el determinismo pasado y habilita un abordaje sin negar el interés predictivo. La condena será una sanción y un tratamiento en cuyos objetivos se incorpora de manera vacilante el conjunto social.

No obstante, el Modelo de Desistimiento encuentra rasgos propios que exigen una lectura aparte, dado que va a permitir "incluir en la retícula conceptual y en sus estrategias de intervención la dimensión política del crimen y su autor" (Rojas Breu, G., 2020: 39). El desistimiento es considerado un proceso (Maruna, 2001; Farrall, 2002; Laub \& Sampson, 2003) que involucra al autor del delito y a la Ilamada "comunidad moral". Consiste en abandonar la conducta delictiva en pos de adherir al marco normativo social, abandono que asume tres niveles: primario, secundario y terciario.

El primero implica un cambio a nivel conductual del autor; el segundo, en la identidad. El nivel terciario invita a aquella comunidad moral a participar del proceso: pues este nivel no se agota en cambios subjetivos (conductuales e identitarios) sino que alcanza la reintegración social que cabalga sobre nivel de pertenencia y aceptación de la mentada comunidad (Trotter, C., Mclvor, G. \& Mc-Neill, F., 2016). Diversas fuentes (Laub \& Sampson 2003; Weaver 2015).

Este tercer nivel es el que permite sostener en el tiempo la adherencia a las leyes que regulan la comunidad moral en tanto la identidad se estructura de forma gregaria y parte de la misma es la percepción de los demás de la proyección de aquella y del lugar consecuente que se ocupa dentro de la sociedad. El desistimiento, entonces, no es solo un proceso personal, sino también político y social. Por lo tanto, la sanción no solo recae sobre el infractor sino sobre la comunidad que es responsable también de esta integración social en el marco de diversas etapas del proceso de la justicia penal. Por lo tanto, acorde este modelo, la consecuencia jurídica de un acto delictivo encuentra dos asientos: el del condenado y el de su comunidad. Pues el delito es entendido, en parte, como la lesión del 
capital social, lesión que comportará sanciones que no solo impactan en el sujeto infractor sino en el propio entramado social que debe movilizar sus propias cuotas de responsabilidad. Concluyendo, se puede afirmar que el cambio supone el trabajo en el capital humano y en el capital social. Recuperando los términos de la variable indagada en el presente trabajo, se puede entender al acto como una lesión del capital social que tiene por agente no solo al autor directo del delito sino a la comunidad moral que lo integra, recayendo el reproche sobre ambos en el marco de la consecuencia jurídica prevista en la sanción penal. Este modelo complejiza la unidad de análisis pues el desistimiento será acabado en tanto y en cuanto se incluya en su esencia la dimensión no solo subjetiva y social sino, y de manera central, política.

\subsection{La psicología jurídica y la función clínica del derecho}

La psicología jurídica aporta un elemento sustancial para pensar en la responsabilidad penal que atiende al vínculo entre el sujeto y la ley y en esa trama inscribe la posibilidad de la responsabilidad penal en el marco de un diálogo disciplinar:

Cuando hablamos de psicología jurídica tenemos que tener presente que es un campo constituido por el entrecruzamiento de dos discursos: el jurídico y el psicológico. Tenemos el Derecho, que parte de lo general a lo particular y tiende a la objetividad y la Psicología, que va de lo particular a lo general, considerando la subjetividad. (Varela, O., 2020: 21).
La psicología jurídica, entonces, habita dicho entrecruzamiento discursivo que ofrece el camino para interrogar la función estructurante de la ley en el sujeto, la subjetivación de la falta mediante la culpa y el valor de la pena en esta red conceptual compleja. Es decir, esta especialidad dentro de la psicología va a delimitar un criminal en tanto sujeto: unidad de análisis diversa de la del individuo anómalo y peligroso del positivismo o el sujeto racional y dueño de sus actos de la escuela liberal. La psicología jurídica va a develar los nexos íntimos y estructurales entre la ley y la subjetividad preservando esta dimensión no solo amenazada por las concepciones antedichas sino por la consideración del delincuente por vulnerabilidad. El sujeto implicado en su acto estará a salvo del determinismo, del voluntarismo y del avasallamiento en nombre de la estructura social. ¿Cuál es el sujeto desde esta perspectiva? El sujeto que no es ajeno a la causalidad psíquica que en modo alguno debe confundirse con voluntad racional toda vez que este sujeto no es dueño de sus actos, "...esa misma causalidad psíquica indica que el hombre es responsable de la posible deliberación (...), ya que no puede dejar de interrogarse por la implicación e involucración que le cabe en cada uno de sus actos" (Gérez Ambertín, M., 2006: 48). Por lo tanto, el acto cifra al sujeto siendo imposible pensarlo por fuera de él y la responsabilidad es un movimiento de deliberación respecto a esta implicación. De esta manera, la psicología jurídica que piensa al derecho desde su función clínica va a interpelar a un sujeto que a través de su falta puede ser convocado a esta deliberación en el marco de la pena: se piensa en una operación que convoque al sujeto implicado en su acto y 
humanizado en su responsabilidad.

Ahora bien, este maniobra por la cual se trazan coordenadas para la emergencia de la deliberación del sujeto en el encuentro íntimo con su acto comporta una privación: pues la pena "siempre implicará la pérdida de algo valioso para el sujeto" (Varela, O., 2020: 29). La falta se sanciona procurando otra falta, y este es el rasgo atemporal de las penas.

No obstante, que el sujeto decodifique esta privación como una interpelación a su acto no es una consecuencia lineal e inexorable. Contrariamente, la responsabilidad será efecto contingente y no mecánico, efecto subjetivo y no ajeno. Por tal motivo, la función clínica del derecho se cumple al asistirse a la siguiente seriación: tras el acto delictivo que comporta una reacción penal es dable asistir a una implicación subjetiva dado que la sanción penal logra subjetivizarse en relación con el acto y "de esta manera la subjetividad inscribe una articulación entre su falta y lo que señala la ley" (Gérez Ambertín, M., 2006: 52).

La consecuencia jurídica del acto lesivo, la pena, entonces, será el vector que permita inscribir la articulación entre la lesión y la ley. En este sentido, es elocuente la distinción entre sanción penal y castigo: la penalización debe pensarse instancia en la cual el sujeto interpelado por la legalidad objetivice y subjetivice su falta: la pena no debe degradarse a la dimensión del castigo sino que obedece a la dimensión de la deliberación (Gérez Ambertin, M., 2006: 53). Si el penado no logra la subjetivación de la falta, la pena carece de sentido:
Se trata, entonces, de subjetivar el crimen, asumir la responsabilidad consecuente y la pena que corresponde, de tal modo el reo sutura, por así decirlo, su relación con el marco social en el que vive encontrando a partir de ello el verdadero sentido de la pena (Sarrulle, O., 2006: 35-36).

La pena, entonces, al señalar el acto delictivo contribuiría a reponer el lazo del sujeto con el tejido social que lo convierta en culpable, es decir, que le permita inscribirse a partir de la culpa en el marco social que lo sanciona. Desde esta perspectiva, el delito será un acto objetivo que porta una verdad subjetiva y la consecuencia jurídica tendrá por fin recuperar la dimensión subjetiva y su lazo con el entramado social que señala el acto como lesivo. La responsabilidad penal se repensará a la luz de la dimensión del sujeto, distinta del Yo: "¿Por qué no interpelar el concepto de responsabilidad penal a partir del esclarecimiento que aporta la experiencia subjetiva vinculada a la posición del sujeto con relación a lo ajeno in-a-propiable que habita al interior del yo?" (Llull Casado, V., 2020: 70).

La responsabilidad penal, entonces, debe traccionar a la responsabilidad subjetiva para que la pena tenga sentido. El reproche recaerá sobre el infractor pero para restar consistencia a este rótulo y habilitar la deliberación que revele la implicación del sujeto.

La pena, entonces, no agota su explicación en términos jurídicos que por definición habitan lo universal (prevención especial positiva y negativa, general positiva o negativa, retribución, etc.). La psicología jurídica abona sustento al respecto al conocer la lógica 
del derecho y al mismo tiempo producir un discurso propio que pueda responder a los requerimientos que se le formulen (Varela, O., 2020: 29). Así, apoyada en sus propias columnas conceptuales, piensa en la pena como posible habilitación de andariveles simbólicos allí donde el padecimiento subjetivo se cifra en acto delictivo, como instancia de promoción de condiciones que permitan la preservación de la dimensión subjetiva allí donde la ley, el estigma y el imperativo social universalizan (Rojas Breu, G. \& Marqués, R., 2020: 128).

\section{CONCLUSIONES}

La responsabilidad penal responde a la lógica del constructo. Su sentido se completa desde diversas coordenadas de enunciación que ofrecen reconstrucciones diversas e impactan de manera sustancial en el tratamiento del delito y de la pena. Del relevamiento expuesto, no obstante, es dable extraer un elemento recurrente: el ostracismo al que es compelida la dimensión subjetiva. Diversas unidades de análisis operan esta expulsión, lo cual ubica a la psicología jurídica en posición de recuperar y preservar aquella dimensión para que la pena no sea degradada a la lógica del castigo.

El sujeto privado de la libertad en el marco de la pena ha sido también privado de su propia implicación en aras de postular una libertad hipostasiada, un determinismo predictor o la por el celo de la reacción penal. Todos los esfuerzos por reponer las elipsis solidarias de los reduccionismos son fundamentales, pero no pueden negar al sujeto que se muestra en su acto, pues no hay posibilidades de resocialización si no hay lugar para dicho sujeto.

\section{TRABAJOS CITADOS}

Andrews, D. A. \& Bonta, J. (1994). The psychology of criminal conduct [La psicología de la conducta delictiva]. ( $1^{\text {a }}$ ed.). Anderson.

Anitua, G.I. (2005). Historia de los pensamientos criminológicos. Ed. Del Puerto.

Baratta, A. (2004). Criminología crítica y crítica del derecho penal. Introducción a la sociología jurídico penal. Siglo.

Basaglia, F. (1987). Los crímenes de la Paz. Siglo XXI

Beccaria, C. (1764). De los delitos y de las penas. Aguilar.

Carrara, F. (1889). Programa del curso derecho criminal. Lucca

Elbert, C.A. (2010). Manual básico de criminología (4ta ed.). Eudeba

Farrall, S. (2002). Rethinking What Works with Offenders: Probation, Social Context and Desistance from Crime [Repensar lo que funciona con los delincuentes: libertad condicional, contexto social desistimiento del crimen]. Willan Publishing.

Ferri, E. (1884). Sociología criminal. Centro editorial del Góngora, 1907

Garofalo, R. (1885). La criminología. Estudio sobre el delito y la teoría de la represión. Olejnik

Gerez Ambertín, M. (Ed.). (2004). Culpa, responsabilidad y castigo. (Vol. 1). Buenos Aires: Letra Viva.

Gerez Ambertín, M. (Ed.) (2006). Culpa, responsabilidad y castigo. (Vol. 2). Buenos Aires: Letra Viva.

Gerez Ambertín, M. (Ed.) (2010). Culpa, responsabilidad y castigo. (Vol. 3). Buenos Aires: Letra Viva.

Grispigni, F. (1947). Derecho penal italiano. (1 ra Ed.). Giuffré

Grüner, E. (2007). Las formas de la espada. Miserias de la teoría política de la violencia. Colihue.

Heller H. (1992). Teoría del Estado. FCE.

Laub, J., y Sampson, R. (2003). Shared Beginnings, Divergent Lives: Delinquent Boys to Age Seventy [Comienzos compartidos. Vidas divergentes: jóvenes delincuentes hasta los setenta años]. Harvard University Press.

Lombroso, C. (1876). L' uomo delincuente [El hombre delincuente]. Ulrico Hoepli editore. 
Llull Casado, V. (2015). ¿Enajenados? Responsabilidad en la locura criminal. Buenos Aires: Letra Viva

Llull Casado, V. (2019). Las coordenadas del crimen. Entre época y estructura. Letra Viva

Llull Casado, V. (2020). Teoría del delito y función del perito psicólogo. En O. H. Varela (Ed.). Psicología Jurídica. 30 años construyendo saberes. (pp. 61-75). JCE Ediciciones.

Martinson, R. (1979). New Findings, New Views: A note caution regarding sentencing reform [Nuevos hallazgos, nuevos puntos de vista: una nota de advertencia sobre la reforma de las sentencias]. Hofstra Law Review, 7(2): 243-258.

Maruna, S. (2001). Making Good [Haciendo bueno]. American Psychological Association.

Pavarini M. (1983). Control y dominación. Teorías criminológicas burguesas y proyecto hegemónico. Siglo XXI.

Prieto, M.P. (2004). Criminología. Ediar

Pujó, M. (2010). Crímenes y pecados. Psicoanálisis y el hospital, 38: $92-100$

Rodríguez, J. (2021). La responsabilidad de los adolescentes infractores. Trabajo inédito.

Rojas Breu, G., Marqués, R. (2020). Sujetos atravesados por las transgresiones. En O.H. Varela (Ed.). Psicología Jurídica. 30 años construyendo saberes (pp. 101-132). JCE.

Rojas Breu, G. (2020). Criminología del acto, política o de autor: las fórmulas de la sinécdoque y el imperativo de integración [Trabajo libre]. XII Congreso Internacional de Investigación y Práctica Profesional en Psicología. XXVII Jornadas de Investigación. XVI Encuentro de Investigadores en Psicología del MERCOSUR.. Facultad de Psicología Universidad de Buenos Aires. Buenos Aires, Argentina. https://www.aacademica.org/000-007/865

Sarrulle, O. (2006) El sentido de la pena en el derecho penal argentino. La culpabilidad en el derecho. En M. Gérez Ambertín (Ed.). Culpa, responsabilidad y castigo. Vol. 1 (pp. 31 -36). Letra Viva.

Simonetti, J.M., Virgolini, J. (2003). Criminología, política y mala conciencia. Editores de Puerto.

Tendlarz, S. y García, C. (2008). A quién mata el asesino. Grama ediciones

Trotter, C., Mclvor, G. \& Mc-Neill, F. (Eds.) (2016). Beyond the
Risk Paradigm in Criminal Justice [Más allá del paradigma del riesgo en la justicia penal]. Palgrave Macmillan

Varela, O.H. (Ed.). (2020). Psicología jurídica. 30 años construyendo saberes. JCE Ediciones.

Virgolini J. (2005). La razón ausente: ensayo sobre criminología y crítica política. Ediciones del Puerto

Weaver, B. (2015). Offending and Desistance [Ofensa y desistimiento]. Routledge.

Zaffaroni R.E. (2003). Criminología: aproximación de un margen. Bogotá: Editorial Temis.

Zaffaroni, E., Slokar, A. y Alagia, A. (2002). Derecho Penal. Parte General. Ediar.

Zaffaroni, E. R. (2005). En busca de las penas perdidas (Deslegitimación y dogmática jurídico-penal). Ediar

Zaffaroni, E. (2011). La palabra de los muertos: conferencias de criminología cautelar. Ediar.

Zaffaroni, E. (2012). Estructura básica del derecho penal. Ediar.

\section{Osvaldo Héctor Varela}

Afiliación: Universidad de Buenos Aires, Argentina. Lic. en Psicología, Universidad John F. Kennedy, Licenciado en Criminología, (USAL) Especialista en Criminología (UPFA), Especialista en Psicología Clínica (UK), Especialista en Psicología Jurídica y Forense con orientación en Delincuencia y Criminalidad (Colegio de Psicólogos de la Policía de Buenos Aires), Dr. en Ciencias Penales (UK). Profesor Universitario de Psicología (UBA)

\section{Gabriela Rojas Breu}

Afiliación: Universidad de Buenos Aires, Argentina. Docente investigadora Psicóloga Clínica Forense, Criminóloga, Servicio Penitenciario Federal Universidad de Buenos Aires, Justicia Nacional Especialista en Diagnostico.

Acerca de la responsabilidad penal: reconstrucción y sistematización de sus acepciones teórico-conceptuales en el campo de la criminología. PP. 7-26 